\title{
Вклад молекулярных данных в современное представление о филогении и биоразнообразии рода Paeonia (Paeoniaceae)
}

\section{Contribution of molecular data to current concepts of phylogeny and biodiversity of Paeonia (Paeoniaceae)}

\author{
Дегтярева Г. В. ${ }^{1}$, Ефимов С. В. ${ }^{1}$, Терентьева Е. И. ${ }^{1}$, Самигуллин Т. Х. ${ }^{2}$, Вальехо-Роман К. М. ${ }^{2}$ \\ Degtjareva G. V. ${ }^{1}$, Efimov S. V. ${ }^{1}$, Terentieva E. I. ${ }^{1}$, Samigullin T. H. ${ }^{2}$, Valiejo-Roman C. M. ${ }^{2}$ \\ ${ }^{\prime}$ Ботанический сад биологического факультета МГУ имени М. В. Ломоносова, г. Москва, Россия. \\ E-mail: efimov-msu@yandex.ru,degavi@mail.ru,el.terenteva@mail.ru \\ ${ }^{2}$ НИИ физико-химической биологии им. А. Н. Белозерского МГУ им. М. В. Ломоносова, г. Москва, Россия. \\ E-mail:samigul@belozersky.msu.ru,vallejo@genebee.msu.su \\ ${ }^{1}$ Botanical Garden, Biological Faculty, M. V. Lomonosov Moscow State University, Moscow, Russia \\ ${ }^{2}$ A. N. Belozersky Institute of Physico-Chemical Biology, M. V. Lomonosov Moscow State University, Moscow, Russia
}

\begin{abstract}
Peфepam. В статье приводится обзор современного состояния молекулярно-филогенетических исследований рода Раеопіа. Молекулярные данные внесли существенный вклад в решение вопросов филогении и систематики рода, подтвердив выделение Paеопіа в качестве самостоятельного монотипного семейства, установив его положения в порядке Saxifragales, и подтвердив естественность внутриродовой классификации с выделением трех секций. Однако высокая степень дивергенции нуклеотидных последовательностей затрудняет установление родственных взаимоотношений Paeоnia с другими семействами, а также между секциями в пределах рода. Одновременно с этим существует проблема точного определения видового статуса. Тем не менее, молекулярные маркеры обладают значительно более выраженной дискретностью по сравнению с морфологическими признаками в роде Paеопіа и помогают разделить ситуации, когда наблюдаемые различия обусловлены фенотипической изменчивостью, а когда имеют место генетически закрепленные морфотипы.
\end{abstract}

Ключевые слова. Молекулярная филогенетика, морфология, пластидный геном, цветковые растения, ITS ядрДНК.

Summary. The article provides an overview of the current state of molecular phylogenetic studies of the genus Paeonia. Molecular data contributed significantly to developing a phylogeny and systematics of Paeonia, and confirmed its status as a separate monotypic family, established its position in Saxifragales, and confirmed the naturalness of currently accepted intrageneric classification. However, high level of nucleotide sequence divergence makes it difficult to establish relationships between Paeonia and other families, as well as between sections within the genus. In comparison to morphological data, molecular data allow differentiating more accurately the species and help to separate situations when the observed differences are due to phenotypic variability, and when genetically fixed morphotypes occur.

Key words. Angiosperms, molecular phylogenetics, morphology, plastid genome, nrDNA ITS.

Paeonia L. - один из сложных в систематическом отношении родов цветковых растений. Детальное изучение морфологии и анатомии, дополненное данными фитохимии и цитологии, тем не менее, оставило много неясного в вопросах таксономии рода и установлении его родственных связей. Трудности систематики Paeonia на основе морфологических признаков обусловлены его своеобразием, проявляющимся в сочетании примитивных, продвинутых и уникальных признаков. Поэтому изучение филогении и биоразнообразия Paеопіа продолжает оставаться актуальным, особенно в контексте современных тенденций развития систематики растений, когда особое значение приобретает понимание того, насколько морфологические и молекулярные данные, рассматриваемые вместе, помогают в решении поставленных задач. Данная статья представляет собой обзор достижений последних лет в изучении систематики Paeonia, полученных с применением молекулярных методов. 
Род Paеопіа включает около 35 видов, распространенных в Европе, Среднеземноморье, Центральной и Восточной Азии, западных районах Северной Америки. Среди видов преобладают многолетние травы, но есть и листопадные геоксильные кустарники. Цветки пионов крупные терминальные, обоеполые, с большим числом тычинок и варьирующим числом чашелистиков, лепестков и плодолистиков. Особое своеобразие рода проявляется в эмбриогенезе, на первых этапах которого деление ядер не сопровождается цитокинезами, а также наличии нектарного диска, расположенного между тычинками и плодолистиками (Тахтаджян, 1987). Центром происхождения рода полагают юго-запад Китая, где наряду с видовым разнообразием наблюдается разнообразие жизненных форм.

Систематическое положение Paeonia долгое время выступало предметом дискуссий, и оставалось неясным, следует ли его выделять в качестве самостоятельного семейства. Благодаря наличию полимерного андроцея и спирального заложения частей цветка, Paeоnia часто сближали с семействами Ranunculaceae или Dilleniaceae. В настоящее время согласно молекулярным данным род Раеопia помещается в порядок Saxifragales (Angiosperm Phylogeny Group, 2016), не родственный порядку Ranunculales. Молекулярные данные подтверждают выделение пионовых из лютиковых и их обособление в качестве самостоятельного семейства. Однако в системе покрытосеменных порядок Saxifragales располагается в так называемом ядре высших двудольных, у представителей которого наблюдается тенденция к формированию пентамерных цветков с круговым расположением частей (Endress, 2011). В роде пион мы наблюдаем спиральное заложение частей цветка, часто без ясных границ между брактеями, чашелистиками и лепестками, больше свойственное наиболее архаичным цветковым растениям. Принимая во внимание молекулярные данные, предполагают (Ronse De Craene, 2010), что у пионовых наблюдается не сохранение примитивного состояния признака, а скорее продвинутое состояние, связанное с нарушением генетических границ между различными кругами, вызванное увеличением числа тычинок. Более того, вторичность полимерного андроцея пионовых доказывают тем, что он закладывается в виде 5 первичных примордиев, на которых затем возникают зачатки отдельных тычинок.

Несмотря на то, что молекулярные данные уверенно помещают семейство пионовые в порядок Saxifragales, тем не менее, внутри порядка родственные связи пионовых устанавливаются пока недостаточно однозначно (Ефимов и др., 2018; Dong et al., 2018). Проблема неустойчивого положения Paeonia на филогенетических деревьях связана с тем, что ветвь, ведущая к пиону достаточно длинная. Различия в топологиях зависят от метода реконструкции дерева. На дереве, построенном с помощью метода Байеса, представители Наmamelidaceae + Altingiaceae группируются вместе с кладой, объединяющей виды Paeonia, в то время как на дереве, построенном с помощью метода максимальной экономии, Hamamelidaceae + Altingiaceae примыкает к группе, включающей Bergenia Moench, Heuchera L., Sedum L. и Penthorum L., при этом Paeоnia занимает изолированное положение, образуя сестринскую группу к остальным представителям порядка Saxifragales (Ефимов и др., 2018). Возможной причиной, объясняющей различия в топологиях, является то, что при реконструкции взаимоотношений методом Байеса учитывается гетерогенность скоростей накопления замен. Это особенно важно учитывать, когда объекты различаются по длинам ветвей, как в данном случае, когда ветвь, ведущая к пиону достаточно длинная.

Рассмотрим теперь соотношение морфологических и молекулярных данных в отношении внутриродовой классификации Paeonia. Согласно наиболее популярной концепции (Stern, 1946; см. обзор Hong, 2010), в основу которой положены жизненные формы и географическое распространение, род подразделяется на три секции: Moutan DC. (около 9 видов, геоксильные кустарники, эндемики Китая), Paeonia DC. (около 23 видов, травянистые растения Старого Света) и Onaepia Lindl. (2 вида, травянистые растения Нового Света). На филогенетических деревьях, построенных на основании различных молекулярных маркеров (Sang et al., 1997a; Sang et al., 1997b), включая полные пластидные геномы (Samigullin et al., 2018), представители рода формируют три четко очерченные клады с высокими уровнями поддержки, которые хорошо согласуются с традиционными представлениями в отношении подразделения рода на группы. Однако взаимоотношение между секциями остается неясным. Как и в случае взаимоотношения Paeоnia с другими семействами, трудности в установлении связей между секциями вызваны высоким уровнем дивергенции представителей секции Onaepia. Наиболее вероятно, 
секция Onaepia занимает сестринское положение по отношению к секции Moutan, включающей древовидные виды.

Много неясного в систематике Paeonia существует в отношении понимания объема видов. Высокая морфологическая пластичность, усугубляемая процессами гибридизации и полиплоидизации, подтвержденными также и молекулярными данными (Sang et al., 1995; Sang et al., 1997a; Sang et al., 2004; Pan et al., 2007; Punina et al., 2012), затрудняет установление границ между видами. По этой причине виды часто объединяются в комплексы. Для изучения взаимоотношений видов рода Рaеопіа привлекали нуклеотидные последовательности различных участков ДНК, среди которых малокопийные гены ядерной ДНК (Adh, GPAT), гены хлоропластной ДНК (rbcL, matK), межгенные спейсеры хлоропластной ДНК (trnL-trnF, psbA-trnH, trnK-matK), а также спейсеры ядерной рибосомной ДНК (ITS) (Sang et al., 1995; Sang et al., 1997a; Sang et al., 1997b; Tank, Sang, 2001; Sang et al., 2004; Pan et al., 2007; Punina et al., 2012). Так, основываясь на различиях в топологиях филогенетических деревьев, построенных по ядерным и хлоропластным участкам, сделан вывод о гибридном происхождения вида $P$. anomala, возникшим от скрещивания P. veitchii Lynch и P. lactiflora Pall. (Pan et al., 2007). Нами были изучены нуклеотидные последовательности ITS ядерной рибосомной ДНК у большого числа образцов из разных точек ареала для некоторых видов и видовых комплексов, произрастающие на территории России: комплекс P. obovata (Восточная Азия: P. obovata Maxim., P. oreogeton S.Moore, P. japonica (Makino) Miyabe et Takeda, $P$. vernalis Mandl. и P. willmottiae Stapf), комплекс $P$. anomala (Сибирь, Средняя Азия и прилегающие регионы: P. anomala L., P. intermedia C.A.Mey., P. hybrida Pall., P. sinjangensis K. Y. Pan, P. altaica K. M. Dai et T. H. Ying и P. veitchii), P. lactiflora (Китай, Монголия и прилегающие регионы России), P. tenuifolia L. (Южная и Юго-Восточная Европа). В целом, можно заключить, что виды характеризуются не только специфичными заменами в ITS, но и мутациями, проявляющимися в виде дополнительных нуклеотидов. Такие нуклеотиды характеризуют группу видов в целом (Paeonia obovata комплекс и P. intermedia + P. hybrida) или отдельные виды (P. intermedia, P. hybrida, P. anomala, P. tenuifolia и P. lactiflora). Согласно комбинации полиморфных позиций, комплекс Paeonia obovata может быть подразделен на три подгруппы, которые не коррелируют с морфологическими признаками и немного коррелируют с географией и уровнем плоидности. Наименьшее число полиморфных позиций наблюдается у образцов с Сахалина и Южного Сихотэ-Алиня. Наличие дополнительных нуклеотидов в некоторых случаях свидетельствует о гибридном происхождении вида (например, P. anomala). Однако подавляющее большинство дополнительных нуклеотидов не обнаружено у других видов, которые могут рассматриваться в качестве родительских форм, и объяснить их наличие результатом гибридизации не получается.

Рибосомная ДНК присутствуют в геноме в виде тандемно расположенных и многократно повторенных копий, подвергающихся периодической гомогенизации, известной как согласованная эволюция (Álvarez et Wendel, 2003), т.е. вновь возникшие мутации либо быстро удаляются, либо распространяются по всем копиям при помощи механизма неравного кроссинговера. Возможно, дополнительные нуклеотиды, наблюдаемые в ITS у Paеопіа, свидетельствуют не только о возможных актах гибридизации, но и отражают современную диверсификацию группы. Скорее всего, это переходное состояние от одного нуклеотида к другому и границы групп, которые либо соответствуют виду, либо характеризуют определенные популяции, находятся в настоящее время на стадии оформления. Данные по пластидным геномам (Samigullin et al., 2018) также свидетельствуют в пользу современной диверсификации Раеоnia, демонстрируя низкий уровень генетической дивергенции между видами в пределах секций.

Таким образом, можно заключить, что в роде Paeоnia морфологические и молекулярные данные как источники систематики достаточно хорошо согласуются между собой на разных таксономических уровнях. Успехи в применении молекулярных данных связывают с выделением Paeonia в качестве самостоятельного семейства и установлением его положения в порядке Saxifragales. Также была подтверждена естественность внутриродовой классификации, основанная на выделении трех секций. Однако своеобразие, которое затрудняло установление родственных связей Paеопia на морфологическом уровне, оказывает негативное влияние и на молекулярном уровне. Так, высокая степень дивергенции нуклеотидных последовательностей затрудняет установление родственных взаимоотношений с други- 
ми семействами, а также между секциями в пределах рода. При этом многие важные вопросы эволюционной морфологии (например, направление эволюции жизненных форм, как на уровне порядка, так и на уровне рода) и биогеографии остаются неразрешенными. Также трудной остается проблема точного определения видового статуса в отношении некоторых таксонов. Тем не менее, молекулярные маркеры обладают значительно более выраженной дискретностью по сравнению с морфологическими признаками в роде Paeonia и помогают разделить ситуации, когда наблюдаемые различия обусловлены фенотипической изменчивостью, а когда имеют место генетически закрепленные морфотипы.

Благодарности. Работа выполнена в рамках госзадания МГУ имени М.В.Ломоносова (темы № АAАA-A16-116021660099-5 и 01201353074) и проекта МГУ "Ноев ковчег".

\section{ЛИТЕРАТУРА}

Ефимов С. В., Дегтярева Г. В., Терентьева Е. И., Самигуллин Т. Х., Вальехо-Роман К. М. Современные данные о родственных взаимоотношениях рода Рaеonia (Раeoniaceae) // Проблемы ботаники Южной Сибири и Монголии: Сб. науч. ст. по материалам XVII междунар. науч.-практ. конф. (24-27 мая 2018 г., Барнаул). - Барнаул: Изд-во АлтГУ, 2018. - С. 414-417.

Тахтаджян А. Л. Система магнолиофитов. - Л.: Наука, 1987. -439 с.

Álvarez I., Wendel J. F. Ribosomal ITS sequences and plant phylogenetic inference // Mol. Phylogenet. Evol., 2003. - Vol. 29. - P. 417-434.

Angiosperm Phylogeny Group. An update of the Angiosperm Phylogeny Group classification for the orders and families of flowering plants: APG IV // Bot. J. Linn. Soc., 2016. - Vol. 181. - P. 1-20.

Dong W., Хи Ch., Wu P., Cheng T., Yu J., Zhou Sh., Hong D. Y. Resolving the systematic positions of enigmatic taxa: manipulating the chloroplast genome data of Saxifragales // Mol. Phylogenet. Evol., 2018. - Vol. 126. - P. 321-330.

Endress P. K. Flower structure and trends of evolution in eudicots and their major subclades // Ann. Missouri Bot. Gard., 2010. - Vol. 97. - P. 541-583.

Hong D. Y. Peonies of the world: taxonomy and phytogeography. - London, UK: Royal Botanic Gardens, Kew, 2010. -302 p.

Pan J., Zhang D., Sang T. Molecular phylogenetic evidence for the origin of a diploid hybrid of Paeonia (Paeoniaceae) // Am. J. Bot., 2007. - Vol. 94. - P. 400-408.

Punina E. O., Machs E. M., Krapivskaya E. E., Kim E. S., Mordak E. V., Myakoshina Yu. A., Rodionov A. V. Interspecific hybridization in the genus Paeonia (Paeoniaceae): polymorphic sites in transcribed spacers of the $45 \mathrm{~S}$ rRNA genes as indicator of natural and artificial peony hybrids // Russ. J. Genet., 2012. - Vol. 48. - P. 684-697.

Ronse De Craene L. P. Floral Diagrams. An Aid to Understanding Flower Morphology and Evolution. - Cambridge: Cambridge University Press, 2010. -441 p.

Samigullin T. H. Logacheva M. D., Degtjareva G. V., Efimov S. V., Terentieva E. I., Vallejo-Roman C. M. Complete plastome sequence of Paeonia lactiflora Pall. (Paeoniaceae: Saxifragales) // Mitochondrial DNA Part B, 2018. - Vol. 3. - P. 1110-1111.

Sang T., Crawford D. J., Stuessy T. F. Documentation of reticulate evolution in peonies (Paeonia) using internal transcribed spacer sequences of nuclear ribosomal DNA: implications for biogeography and concerted evolution // Proc. Natl. Acad. Sci. USA, 1995. - Vol. 92. - P. 6813-6817.

Sang T., Crawford D. J., Stuessy T. F. Chloroplast DNA phylogeny, reticulate evolution, and biogeography of Paeonia (Paeoniaceae) // Am. J. Bot., 1997a. - Vol. 89. - P. 1120-1136.

Sang T., Donoghue M. J., Zhan D. Evolution of alcohol dehydrogenase genes in Peonies (Paeonia): phylogenetic relationships of putative nonhybrid species // Mol. Biol. Evol., 1997b. - Vol. 14. - P. 994-1007.

Sang T., Pan J., Zhang D., Ferguson D., Wang C., Pan K. Y., Hong D. Y. Origins of polyploids: as example from peonies (Paeonia) and a model for angiosperms // Biol. J. Linn. Soc., 2004. - Vol. 82. - P. 561-571.

Stern F. C. A study of the genus Paeonia. - London: Royal Horticultural Society, 1946. - 155 p.

Tank D. C., Sang T. Phylogenetic utility of the glycerol-3-phosphate acyltransferase gene: evolution and implications in Paeonia (Paeoniaceae) // Mol. Phyl. Evol., 2001. - Vol. 19. - P. 421-429. 